\title{
Palabras de la Dra. Lastenia María Bonilla, directora de la Revista Educación, en conmemoración del 40 aniversario de la Revista
}

Señora Decana Dra. Alejandrina Mata

Señora Dra. Adriana Venegas, Directora de la Escuela de Administración Educativa

Señor Roberto Vargas Dengo

Señora Ana Isabel Vargas Dengo

Señora Flor de María Pérez, primera directora de la Revista Educación

Señora Saray Córdoba, encargada de UCRIndex y Latindex para Costa Rica

Señores y señoras exdirectoras y exeditoras

Señores y señoras integrantes del Comité Editorial de la Revista Educación

Público presente

Hoy estamos aquí para celebrar los 40 años de la Revista Educación y esto ha sido posible solamente porque se han venido concatenando una serie de eslabones que han permitido llegar a este importante y significativo momento.

Algunos de esos eslabones están aquí representados:

- Directores y directoras

- Editoras

- Decanos y decanas

- Personas autoras

- Revisores y revisoras

- Por supuesto, público lector

- Personas que han conformado los diversos Comités Editoriales y que proceden actualmente de cada una de las Escuelas de la Facultad. Es interesante aquí recordar que doña María Eugenia Dengo, a quien hoy recordamos, fue una de las personas que integró el primer Comité Editorial.

A cada uno de ellos y de ellas hemos de agradecerles su labor.

Sé que no ha sido fácil y sé que no seguirá siendo fácil continuar sin interrupción esta cadena hasta llegar a celebraciones de 60, 80 o 100 años de esta Revista, pero vale la pena continuar con este esfuerzo. Esta es una joya que engalana a la Facultad de Educación, y debemos apoyarla como hasta ahora ha sido.

Unos pocos datos permiten mostrar esta alhaja:

- La Revista Educación impresa permitió a la Biblioteca de la UCR, 106 canjes; es decir, se recibían 106 volúmenes de otras revistas a cambio de un volumen de la Revista Educación. 
- Además, según las estadísticas de Google Analytics para la página web, en este año que no ha finalizado:

- Ha habido 106.811 sesiones.

- 88.070 personas usuarias la han visitado.

- 221.063 número de visitas a páginas.

- Los lectores y lectoras, mayoritariamente, proceden de los siguientes países: México, Costa Rica, Colombia, Perú, España, Argentina, Chile, Ecuador, Venezuela y Guatemala.

- El promedio anual de ingreso de artículos ha aumentado en los últimos años. Este año ya han ingresado más de 80 .

- El pdf de un artículo de la profesional Guiselle María Garbanzo Vargas, sobre el rendimiento académico en estudiantes universitarios, ha sido visto 66195 veces entre el 2014 y el 2016, y ha sido citado 248 veces según Google Académico.

- Según Google Académico, en el 2016, se han citado 133 artículos de la Revista.

También es bueno irnos a ese lejano primer volumen, en el cual encontramos aspectos interesantes que para algunas personas podrían ser 'sorprendentes', pues consideran que lo escrito hace 40 años en una revista ya nadie lo leería. Pero veamos la realidad actual con respecto a este volumen:

- Encontramos en primer lugar una semblanza de Emma Gamboa escrita por doña María Eugenia Dengo, la cual ha sido vista 90 veces entre 2015 y 2016.

- El artículo de Emma Gamboa: Libros de texto básicos para la enseñanza de la lectura, ha sido visto 390 veces en esos mismos dos años.

- Además, encontramos artículos de:

- Victoria Garrón de Doryan, que llegó a ser Vicepresidenta de nuestro país con 87 vistas. El tema es: La educación permanente.

- De Sonia Carballo de Hernández, cuyo artículo se tituló: Enseñanza centrada en el alumno con 180 visitas.

- Con el tema: La educación especial, escribe Marlenne Rodríguez, quien tuvo 175 vistas solamente en el 2016.

Además, como autor está el reconocido escritor Isaac Felipe Azofeifa, del cual la Editorial Costa Rica dice: Azofeifa constituye un ejemplo categórico y brillante de "poeta por todos los costados".

En 1988 se publica otro artículo de doña María Eugenia Dengo, el cual solamente en el 2016 ha recibido ya 153 visitas.

Esto muestra que lo que se publica en las revistas sigue teniendo vigencia, aunque pase el tiempo. 
Con estos breves y significativos datos en la mente, pasemos inmediatamente al panel que hemos preparado para esta celebración, donde disertarán tres profesionales relacionadas con las revistas, sobre tema afines a la celebración. Contamos con la valiosa colaboración de:

- Licenciada Flor de María Pérez, con el tema: Iniciativa de la creación de una revista

- Máster Saray Córdoba que tratará el tópico: "Estado actual de las publicaciones"

- Y la señora Alejandrina Mata con: Aportes de las revistas a la educación.

Sabiendo que las dejo en muy buenas manos, finalizo.

Gracias. 